\title{
TORNAR-SE UM BUDA: ANÁLISE SEMIÓTICA DE VISUALIZAÇÕES NO BUDISMO TIBETANO ${ }^{1}$
}

\author{
Louis Hébert \\ Louis Hebert@uqar.ca \\ Departamento de Humanidades e Letras \\ Universidade de Quebec em Rimouski (UQAR)
}

Resumo. Este trabalho analisa alguns aspectos do budismo Vajrayāna sob a perspectiva teórica das zonas antrópicas de François Rastier, para quem, o nível semiótico da prática social pode ser articulado em três zonas antrópicas: a identitária, a proximal e a distal. A primeira corresponde, em particular, ao indivíduo, a segunda aos congêneres e a terceira é preenchida com objetos ausentes, imaginários ou desconhecidos. Sem nuances pejorativas, o autor chama fetiches aos objetos da primeira fronteira e ídolos aos da segunda. O corpus analisado consiste, principalmente, em textos do sādhana, onde o praticante é convidado, através de visualizações complexas, a ser transformado, progressivamente, durante a sessão, em um ser iluminado, um Buda, passando, assim, em pensamento, da zona antrópica de identidade para a zona distal, através da mediação de uma divindade budista que tem o status de ídolo.

Palavras chave: Semiótica. Zonas antrópicas. Budismo Vajrayāna.

Abstract. This paper analyzes some aspects of Vajrayāna Buddhism from the theoretical perspective of François Rastier's anthropic zones, for whom the semiotic level of social practice can be articulated into three anthropic zones: the identity, the proximal, and the distal. The first corresponds in particular to the individual, the second to the counterparts, and the third is filled with missing, imaginary, or unknown objects. Without pejorative nuances, the author calls fetishes the objects of the first frontier and idols to those of the second. The analyzed corpus consists mainly of texts of sādhana, where the practitioner is invited, through complex visualizations, to be transformed, progressively, during the session, into an enlightened being, a Buddha, thus passing, in thought, from the zone. of anthropic identity to the distal zone through the mediation of a Buddhist deity who has idol status.

Key words: Semiotics. Anthropic zones. Vajrayāna Buddhism.

\section{Introdução}

Um sādhana é um tipo de prática do Vajrayāna, ou seja, do budismo tântrico indo-tibetano, através do qual o yogi, ou seja, o praticante atinge a natureza do yidam, isto é, da divindade tutelar, o Buda de eleição Em outras palavras:

"[...] é um método completo para obter os poderes (sk:siddhi) ordinários [isto é, milagrosos a serem postos a serviço da compaixão] e supremos [ isto é, o sono, a entrada no nirvāna dinâmico, a erradicação de emoções negativas e cognições errôneas]. Os sādhanas constituem o núcleo central e o tecido estrutural de qualquer ritual tântrico [isto é, baseado em textos budistas chamados "tantras"], seja realizado em grupo ou solitariamente. [...] Os textos de sādhana são organizados como guias que descrevem as visualizações,

\footnotetext{
${ }^{1}$ Tradução por Maria de Fátima Barbosa de Mesquita Batista do original Devenir un Bouddha: analyse sémiotique des visualisations dans le bouddishme tibétain in Semiótica e Cultura: dos discursos aos universos construídos (HÉRBET, 2015).
} 
todas as etapas da prática, os atos rituais a serem realizados, etc. "(Cornu, 2006: 491).

Nos sādhanas que consultamos para este artigo, o praticante é convidado, através de visualizações complexas, a ver-se transformado, progressivamente, durante a sessão, nesse ser desperto, neste Buda que é o yidam, por exemplo, o Avalokiteśhvara, ser revelado' que simboliza a compaixão ou o Padmasambhava, uma figura semilendária que estabeleceu o budismo no Tibete.

À luz da teoria das zonas antrópicas de François Rastier, o praticante passa, portanto, em pensamento - mas com o objetivo de torná-lo realidade e graças a isso da zona de identidade antrópica à zona distal, aquela onde a transcendência habita e isso através da mediação de uma divindade budista. Rastier chama de "ídolo" (sem conotações) esses mediadores entre a zona distal e as duas outras zonas, identitária e proximal.

Essa análise aprofundará nosso conhecimento das sādhanas do tantrismo budista em geral, como também (uma vez que todas as religiões insistem fortemente na zona distal) o nosso conhecimento do fenômeno religioso, especialmente em seu lado místico. Finalmente, a análise possibilitará apresentar essa teoria de Rastier e, igualmente, pensar no modo como aplicá-la ou concebê-la.

Segundo Rastier, o nível (ou a esfera, utilizando-se outra terminologia) da prática social é subdividido em três zonas, denominadas antrópicas porque relacionadas ao homem (do grego anthropos: homem). Apresentamos, primeiro, a teoria das zonas antrópicas de François Rastier, adicionando alguns esclarecimentos e complementos. Estudaremos, em seguida, o caminho percorrido por essas zonas e fronteiras e as transformações de seu inventário de seres, ao mesmo tempo que a progressão do texto de uma sādhana em particular. O budismo é um assunto complicado por milênios de história, múltiplas escolas e numerosos documentos canônicos em vários idiomas.

Quero esclarecer que não sou um "budólogo" (estudioso de Buda ), mas um semioticista, interessado no budismo e que o vem tomando, desde alguns anos, como parte de uma série de publicações (ver Hébert, 2011a a 2011e, nos próximos anos b e c) ${ }^{2}$. Essas publicações um dia incluirão, esperamos, um ensaio sobre o budismo e a semiótica.

\section{Os três níveis ou esferas da prática}

2 O presente texto está publicado em tradução inglesa. A versão francesa encontra-se ligeiramente modificada em relação a esta tradução. 
Para Rastier, a cultura envolve três esferas, embora possamos dizer que a esfera mais característica seja, sem dúvida, a segunda, onde a cultura encontra-se em reflexão. Para superar as deficiências das bipartições ontológicas (por exemplo, o mundo físico/o mundo cognitivo), Rastier propõe a tripartição: esfera física, esfera semiótica e a esfera dos processos mentais ou cognitiva (1994: 4-5 e 1991: 237-243). Aqui está um resumo dessa hipótese: "Uma cultura pode muito bem ser definida como um sistema hierárquico de práticas sociais". (Rastier 1994: 211). Toda prática social é uma atividade codificada, envolvendo relacionamentos específicos entre três esferas (Rastier 1994: 224), ou na nova terminologia, três níveis: 1. Uma esfera física (ou nível fenofísico) constituído pelas interações materiais que lá ocorrem. 2. Uma esfera semiótica (ou nível semiótico) que consiste nos sinais (símbolos, ícones e sinais etc.) que são trocados ou colocados em jogo. 3. Uma esfera de processos mentais (ou nível de (re) apresentações) específicos para agentes e em geral fortemente socializados $^{3}$ (Rastier 1994: 4 e 1991: 237-243).

Nesta tripartição, a esfera semiótica é mediadora entre o mundo físico e o mundo dos processos mentais: o plano de expressão (do significante) que tem correlatos privilegiados na esfera física e o plano do conteúdo (do significado), na esfera mental (Rastier 1994: 5). Os correlatos físicos ligados aos significantes são estímulos (Klinkenberg) e os correlatos cognitivos dos significados são imagens mentais (no significado não exclusivamente visual do termo) ou simulacros multimodais (Rastier). Em seguida, Rastier (2002: 247) especificou sua tripartição, relativizando e especificando a oposição entre Umwelt - o próprio mundo dos indivíduos - e Welt, como esses conceitos são definidos por Uexküll (1956):

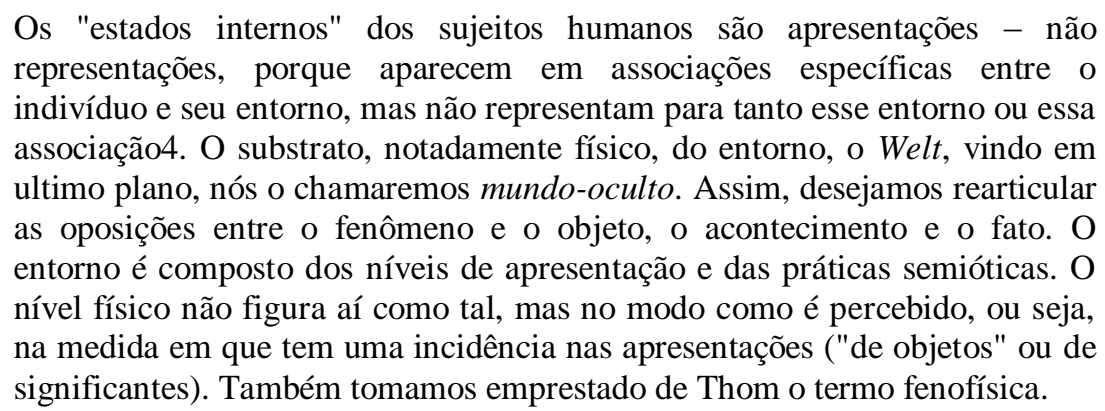

A tripartição toma, então, a forma seguinte (Rastier, 2002:247):

Os três níveis, o entorno e o mundo anterior.

\footnotetext{
3 Os processos mentais, em geral, não são puramente físicos, "naturais", mas estão fortemente determinados, estruturados pelo social, o "cultural".
} 


\title{
Entorno (Umwelt): $\quad$ niveis das apresentações
}

niveis semióticos

Mundo Oculto (Welt):

niveis fenofisicos

\section{As três zonas antrópicas \\ Rupturas e zonas antrópicas}

O nível semiótico se caracteriza por quatro grandes rupturas categoriais cujas homologias entre as zonas que articulam definem três zonas antrópicas (relativas ao homem, do grego anthropos: homem):

\begin{abstract}
O nível semiótico do entorno humano é caracterizado por quatro recuos ou rupturas de grande generalidade e que parecem diferentemente atestados em todas as línguas descritas, de modo que se pode conferir-lhes, por hipótese, um alcance antropológico. [....] As homologias entre estas rupturas permitem distinguir três zonas: uma de coincidência, a zona identitária; uma de adjacência, a zona proximal; uma de distanciamento, a zona distal. A principal ruptura separa as duas primeiras zonas da terceira. Em outras palavras, a oposição entre a zona identitária e a zona proximal é dominada pela oposição que separa estas duas zonas, tomadas em conjunto, com a zona distal. Assim se distinguem um mundo óbvio (formado das zonas identitárias e proximal) de um mundo ausente (estabelecido pela zona distal). As três zonas [....] são criadas, instituídas, povoadas e retrabalhadas sem sessar pelas práticas culturais. [....] Evidentemente, o conteúdo das zonas variam com as culturas e a fortiori com as práticas sociais. (Rastier, 2010:19/20).
\end{abstract}

Mais precisamente, a zona distal é "povoada de objetos ausentes, imaginários ou desconhecidos" (Rastier, inédito: 2012). O quadro abaixo (Rastier, 2002: 249) representam as quatro rupturas e as três zonas:

\begin{tabular}{|c|c|c|c|}
\hline & Z. identitária & Z. proximal & Z. distal \\
\hline Pessoa & EU, NÓS & TU, VÓS & ELE, SE, ISTO \\
\hline Tempo & AGORA & $\begin{array}{c}\text { RECENTE } \\
\text { EM SEGUIDA }\end{array}$ & $\begin{array}{c}\text { PASSADO } \\
\text { FUTURO }\end{array}$ \\
\hline Espaço & AQUI & AÍ & $\begin{array}{c}\text { ALÍ, LÁ, } \\
\text { ACOLÁ } \\
\text { ALHURES }\end{array}$ \\
\hline Modo & CERTO & PROVÁVEL & $\begin{array}{c}\text { POSSÍVEL } \\
\text { IRREAl }\end{array}$ \\
\hline \multicolumn{3}{|c|}{ Ar. Empírica fr. Transcendente } \\
\hline
\end{tabular}

Quanto à ruptura pessoal, lembramos que a terceira pessoa "se define pela sua ausência da interlocução (embora possa estar presente fisicamente)" (Rastier, 2010: 19). Nas zonas distais das rupturas temporais (ou locais) e espaciais, encontram-se elementos que têm como "propriedade que os define o fato de estarem ausentes do hic et nunc" 
(Rastier, 2010: 19), ou seja, do aqui e agora. A zona distal é a única que é específica dos seres humanos, no sentido de que ela caracteriza unicamente a cultura humana:

Em relação às linguagens dos animais, a particularidade das línguas reside, sem dúvida, na possibilidade de falar do que não está lá, ou seja, da zona distal. [....] A zona proximal onde, por exemplo, os congêneres são reconhecidos como tal, também pertence ao entorno dos outros mamíferos por verossimilhança. Em contrapartida, a zona distal, do ponto vista da origem, continua a ser específica do entorno humano, sem dúvida porque ela é estabelecida pelas línguas. A zona distal é, em suma, a fonte de apresentações sem substrato perceptivo imediato. Nos termos familiares da filosofia, a zona proximal é a do empírico e a zona distal, a do transcendente ${ }^{4}$. (Rastier, 2010: 22)

\section{As duas fronteiras entre as zonas}

Entre as três zonas, colocam-se duas fronteiras ou lados fronteiriços:

A fronteira empírica que se estabelece entre a zona identitária e a zona proximal e a fronteira transcendente ocorrida entre estas duas primeiras zonas e a zona distal. Propusemos chamar - sem nenhum matiz pejorativo fetiches os objetos da fronteira empírica e ídolos, os da fronteira transcendente.

A oposição entre empírico e transcendente em 2010 (p.22) é retomada de outro escrito de Rastier de 1992. Lembramos que, em antropologia, um fetiche é um objeto ao qual se atribui um poder mágico (aquilo que chamamos de fetichismo em psicologia é uma perversão sexual); um ídolo é a representação da divindade que é adorada como se ela fosse a própria divindade. O esquema abaixo (Rastier, 2010: 23) representa a organização das fronteiras entre as zonas e correlativamente os cortes entre estas:

Objetos culturais e fronteira antrópicas

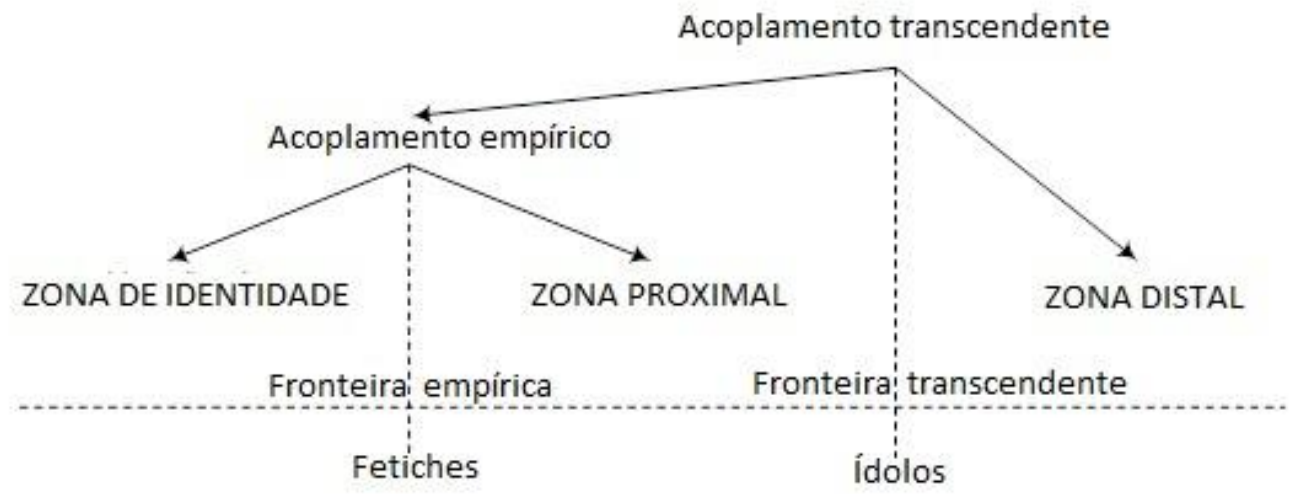

\footnotetext{
${ }^{4}$ A transcendência tem por definição estar fora do mundo. As línguas e, mais geralmente, as semióticas estão evidentemente no mundo, portanto são imanentes. Entretanto, elas podem representar, segundo caso, elementos imanentes ou elementos transcendentes. (Por exemplo, Deus).
} 
O quadro abaixo (adaptado de Rastier, 2010: 22) dá alguns exemplos indicativos de fetiches e ídolos cruzados com o critério das esferas ou níveis:

Os mediadores entre as fronteiras antrópicas

\begin{tabular}{|c|c|c|}
\hline $\begin{array}{c}\text { Fronteiras } \\
\text { Níveis }\end{array}$ & Fronteira empírica & Fronteira transcendente \\
\hline Nível (re)presentacional & Fetiches & Ídolos \\
\cline { 2 - 3 } Semiótico & Fantasmas & Crenças \\
\hline & $\begin{array}{c}\text { sinais (palavras, } \\
\text { ornamentos, moedas, etc.) } \\
\text { ferramentas } \\
\text { objetos de transição } \\
\text { (bonecas etc.) }\end{array}$ & $\begin{array}{c}\text { obras (obras artísticas, } \\
\text { códigos, teorias filosóficas, } \\
\text { científicas e religiosas, } \\
\text { objetos rituais) } \\
\text { instrumentos (musicais, } \\
\text { científicos, rituais, etc.) }\end{array}$ \\
\hline
\end{tabular}

O quadro precedente apresenta uma tipologia dos objetos culturais que se inscrevem dentro da antropologia das "coisas" que Rastier elabora, inspirando-se livremente numa tipologia de Krysztof Pomian (1996):

Distinguiremos, primeiramente, os corpora naturais [ou seja, "toda forma de materialidade e não, unicamente, as sólidas"] os objetos culturais, enfim os resíduos, surgidos da transformação dos corpos em objetos. O percurso de produção vai dos corpora aos resíduos. Os artefatos compreendem os objetos culturais e os resíduos: os primeiros pedem uma interpretação que faz de sua produção uma produção de sentidos; os segundos permanecem na sua insignificância. Os objetos culturais [ou seja, 'todo resultado de uma observação que pode, por sua vez, participar de uma prática social: como, por exemplo, de uma partitura musical"] dividem-se, por seu turno, em três categorias: os utensílios e, os mais completos, os instrumentos (compreendendo como isso também os instrumentos de comunicação como as mídias); os signos (linguísticos ou não: palavras, símbolos, figuras, etc); enfim, as obras, que são originárias de uma elaboração de signos, pelos menos, dos utensílios. Entre os signos e as obras, releva-se uma diferença de complexidade: é a ação combinadas dos utensílios e os signos que permitem produzir as obras [....]. Elas são oriundas do próprio movimento da ação humana que as produz, criando formações mediadoras entre o mundo proximal e o mundo distal: as artes, as religiões e as ciências. (Rastier, 2010: 17 - 19)

O esquema abaixo (Rastier, 2010: 20) apresenta a tipologia esboçada: 


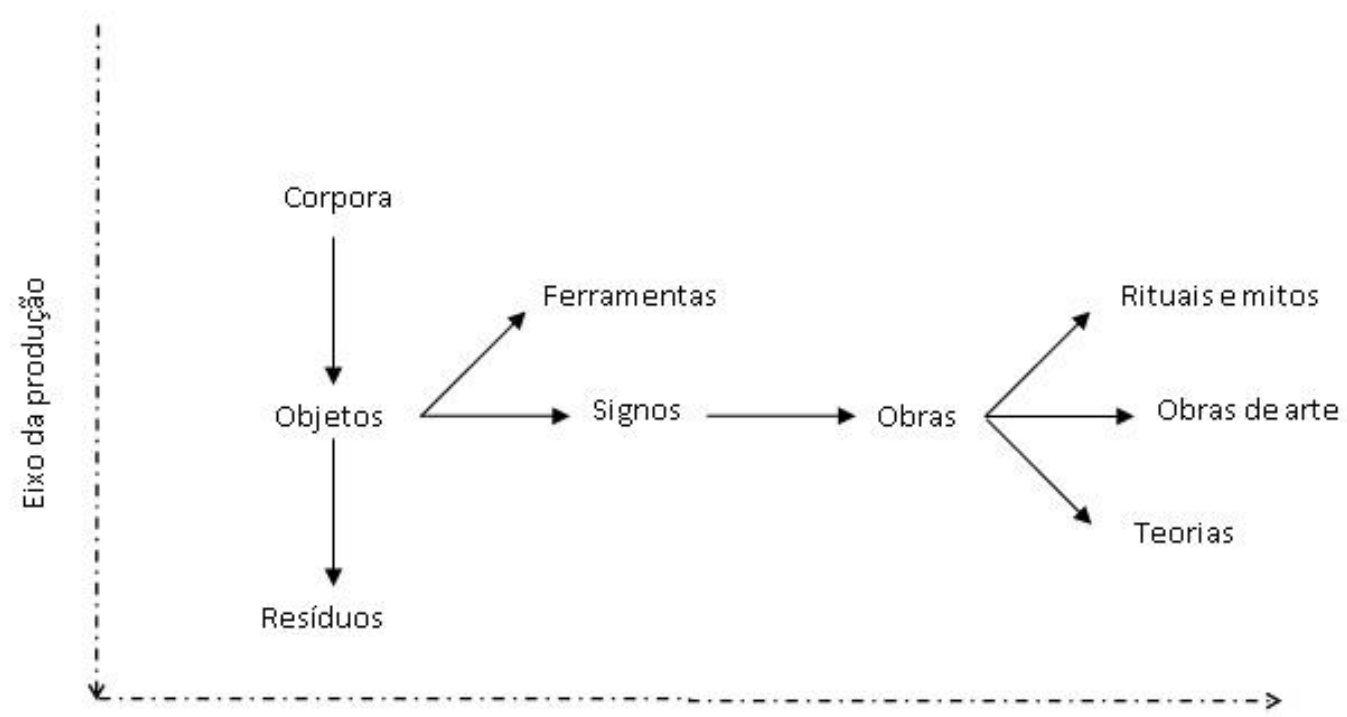

Eixo da criação e da interpretação

\section{Característica do fetiche e do ídolo}

O fetiche e o ídolo não têm em si mesmo uma propriedade objetiva que os estabeleça nesse status. É a "decisão semiótica" (retomando uma expressão de Klinkenberg) que lhes dá esse status.

Naturalmente o fetiche não tem, da mesma forma que o ídolo, nenhuma propriedade objetiva que justifique a fascinação da qual ele é objeto: ele materializa, simplesmente, a fascinação que se agrega a ele de uma maneira tão exclusiva que ele o descontextualiza e o torna um objeto em si que faz emanar um atrativo próprio, sem determinação. Ora, a descontextualização é definidora do absoluto: aquilo que é determinante e não determinado. Assim, o fetiche parece exercer um poder e o exerce efetivamente, pois supera qualquer coisa pela aura de seu poder simbólico e misterioso. (Rastier, 2010: p.47)

As três características do fetichismo são a abstração, a generalização e a amplificação:

Alfred Binet, no passado, divulgou três características do fetichismo, como “concentração" (1887: 107): (1) a tendência à abstração, ou ao desapego, do fetiche nega qualquer contexto (a mulher por inteira está em seus olhos) e o objeto fetiche pode, repentinamente, tornar-se parcial (os olhos, não a mulher inteira); (2) a tendência à generalização parece um resgate dessa abstração (não esses olhos, mas todos os olhos); finalmente (3) uma tendência à amplificação leva, por exemplo, o fetichista de sapatos a apreciar saltos muito altos. A tendência à amplificação pertence à estilização peculiar ao fantasmático. [...] Como vemos, os efeitos reificantes do fetichismo são muito semelhantes aos do neopositivismo: descontextualização, depreciação, invasão obsessiva dos objetos. $\mathrm{O}$ positivismo tem todas as características de uma obsessão que se apresenta na forma benigna de evidência. Mas, 
diferentemente do fetichismo da mercadoria que promoveu os dólares em ídolos e o mercado em deus, a idolatria do Ser conduz, assim, à "degeneração" dos ídolos em fetiches, pequenos objetos descontextualizados e fascinantes. Assim, termos e palavras-chave que parecem resumir tudo, até objetos de hipotipose, do escudo de Aquiles ao boné de Charles Bovary, que brilham diante de nossos olhos em virtude da enargia ${ }^{5}$ descritiva. (Rastier, 2010: 47-48).

\section{Fatores de relatividade}

Diremos que o estatuto dos elementos integrados nas zonas antrópicas afeta, principalmente, as seguintes variáveis: classificação em uma zona e/ou outra, posição mais ou menos próxima/distante nessa zona, natureza ou não de fetiche e/ou ídolo, grau desse tipo de fetiche e/ou ídolo. De fato, as zonas e as fronteiras não têm nada de categorial e podem ser de natureza escalar, gradual e serem dotadas de espessura, como por exemplo, o irreal é, provavelmente, ainda mais distal do que o possível. Tal elemento poderá ser considerado um ídolo de intensidade muito maior do que qualquer outro elemento. Além disso, não está excluído, especialmente nas ficções, que, sendo todos os fatores de relatividade constantes, um mesmo elemento é de uma zona e de outra: ou da natureza do fetiche e da natureza do ídolo, ou da natureza do fetiche e da natureza do não-fetiche e do não- ídolo, etc. O estatuto dos elementos está suscetível à variação em função das culturas e das práticas, conforme apontado por Rastier. Deve-se acrescentar que pode variar de acordo com todos os fatores da relatividade, em particular do observador, tempo, espaço, elementos presentes (por exemplo, um pequeno elemento parecerá ainda menor no contexto de grandes elementos), da perspectiva do casamento (local/global: elemento/classe, ocorrência/tipo, parte/tudo).

Esses estatutos e os fatores de relatividade podem ser "reais" ou tematizados em um produto semiótico (por exemplo, um artigo de jornal, um romance, uma pintura), ou seja, integrado ao conteúdo semântico deste. Por exemplo, os políticos reais mencionados em um artigo de jornal, os personagens de um romance são observadores tematizados e o tempo no qual eles evoluem, o tempo da história em que atuam é igualmente tematizado. É necessário, portanto, distinguir entre fetiches e ídolos reais e fetiches e ídolos tematizados. Os produtos semióticos em si mesmos podem ser fetiches (produtos práticos: por exemplo, receitas, artigos de jornal) ou ídolos (produtos míticos: por exemplo, romances, ensaios); sejam fetiches ou ídolos, os produtos semióticos podem tematizar, isto é, integrarem-se ao seu conteúdo semântico, fetiches e/ou ídolos

\footnotetext{
${ }^{5}$ NT. Do grego enárgeia, «clareza», pelo latim enargia, «descrição pitoresca». A representação tão viva de um objeto, no discurso, que parece que o leitor, ou ouvinte, está a ver o objeto descrito.
} 
indiferentemente. Por exemplo, um artigo de jornal falará sobre jornais (fetiche que tematiza fetiche) ou um romance (fetiche que tematiza ídolo); um romance falará sobre jornais (ídolo que tematiza fetiche) ou de um romance (fetiche que tematiza fetiche). Assim, o mesmo elemento antrópico pode abranger vários elementos de estatuto idêntico ou não ao seu. Por exemplo, a teoria econômica de Adam Smith, portanto um ídolo, contém um elemento que é um hiper-ídolo (já que o ídolo por excelência dentro desse ídolo é uma teoria): a "mão invisível" que deveria regular o mercado. Essa inclusão pode ocorrer entre um elemento "real" e um elemento tematizado, por exemplo: uma obra artística ídolo, como o é um texto literário, falará em meio a fetiches (dinheiro, cotão, por exemplo) e ídolos (por exemplo, outros textos literários fictícios ou não). Isto sem contar que os elementos podem, sem os tematizar, evocar outros elementos (por exemplo, o quadro de uma Vênus que nasce das águas evocará outro quadro sobre o mesmo tema).

Damos alguns exemplos e explicações sobre a natureza dos fetiches/ídolos (reais ou tematizados) que é relativa por que:

(1) pode, antes, variar em função do observador: o que é fetiche, para um, poderá ser ídolo para outro ou, mesmo que se aceite que ídolos e fetiches não constituem uma dicotomia, nem ídolo, nem fetiche.

(2) pode, em seguida, variar em função do tempo. Para um mesmo observador, o fetiche do passado poderá ser promovido a ídolo hoje ou o ídolo do passado retroagirá a fetiche hoje; a unidade nem fetiche, nem ídolo ascenderá, mais tarde, ao estatuto de ídolo, etc. A variação no tempo é causada, em princípio, por uma transformação do sujeito observador e/ou do objeto, ou ainda, do conhecimento que o observador tinha desse objeto (por exemplo, acreditava-se que o elemento era ídolo porque possuía “poderes mágicos” que provaram ser ilusórios).

(3) a natureza fetiches/ídolos pode, igualmente, variar em função da mudança da perspectiva global/local aplicada ao objeto observado, ao sujeito observador e/ou ao tempo de observação. Podem-se distinguir três perspectivas globais/locais: todo/parte, classe/elemento, tipo/ocorrência. Por exemplo, o objeto que é ídolo no nível do todo pode ser fetiche (ou unidade ordinária, nem fetiche nem ídolo) em uma de suas partes ou em várias; o objeto que é ídolo, enquanto classe, pode conhecer um ou vários elementos simplesmente fetiches ou ordinários; o objeto que é ídolo, enquanto tipo, pode ser considerado simples fetiche em uma ou várias de suas ocorrências. O mesmo principio se aplica ao sujeito observador, 
considerado como todo ou em suas partes (por exemplo, o id, o ego e o superego como partes do psiquismo), como classes ou elemento (o conjunto dos Ocidentais ou aquele Ocidental), como tipo ou ocorrência (o Ocidental meio ou tal Ocidental). O mesmo principio se aplica, igualmente, ao tempo, considerado como um todo/parte (tal período e seus subperíodos), como classes/elementos (os períodos de guerra ou tal período de guerra) ou tipo ocorrência (os períodos de guerra em geral ou este período de guerra em particular). Evidentemente, o estatuto de uma unidade pode variar quando se passa de uma localidade a outra; por exemplo, uma unidade será fetiche em alguma de suas partes, mas ídolo em outra. Quando as características locais divergem, pode ser repercutida no teor global de várias maneiras diferentes. Tomemos o tempo e as relações todo/parte. O fato de que aquilo que era ídolo ontem ser fetiche hoje e voltar a ser ídolo amanhã pode ser interpretado simplesmente como uma sequência de estados de duração de uma jornada (ídolo > fetiche > ídolo) sem que aja repercussão num tempo global de duração de três dias. Este fato pode, ao contrário, repercutir num nível global e de três maneiras principais: seja como ídolo-fetiche, seja dando conta da ambiguidade sem ponderação; seja como mais ídolo que fetiche, seja dando conta da preponderância da natureza do ídolo; seja (sem mais nada acrescentar), seja aumentando o valor preponderante (ídolo, atribuído duas vezes) descartando o valor divergente (fetiche atribuído uma vez).

(4) a natureza fetiche/ídolo pode, enfim, variar em função do inventário dos elementos interdefinidos e isto, de uma posição temporal a outra ou, no seio de uma mesma posição temporal, de um observador a outro ou pelo mesmo observador: o que é fetiche relativamente a este ídolo poderá ser ídolo relativamente a este outro fetiche. Por exemplo, relativamente a uma notícia de manutenção de avião, uma receita gastronômica pode ser considerada como uma obra, um ídolo enquanto está sendo vista como um fetiche em relação á $A$ pesquisa do tempo perdido. Esta relatividade interdefinitória, que coloca em cena, pelo menos três elementos, pode ser convertida em uma escala que dá conta da ponderação das partes fetiche/ídolo no seio dos elementos por inteiro. Diferentes escalas são possíveis. Por exemplo, numa escala que vai da fetichidade máxima à idolatria máxima a receita ocupará uma posição intermediaria. Numa escala que vai da idolatria mínima à idolatria máxima, a 
notícia ocupará uma posição mínima (que pode corresponder a uma intensidade nula).

\section{Síntese}

A análise com o dispositivo antrópico consiste em endereçar o inventário (nome, natureza) dos elementos a uma ou várias das cinco posições (três zonas e duas fronteiras) para definir a ou as posições de um ou vários elementos; para endereçar as mudanças de inventário e/ou de posição. A mudança intervém em função dos fatores de relatividade habituais: sujeito observador (indivíduos, grupos, sociedades, culturas, etc); tempo; espaço; passagem de um elemento a outro; transformações do mesmo elemento, variações dos elementos em presença; etc ${ }^{6}$. Mas, devemo-nos lembrar de que estes fatores podem variar sem que uma mudança de inventário e / ou de posição intervenha pela mesma razão (por exemplo, dois sujeitos observadores diferentes podem estar de acordo sobre a posição sobre esse elemento). Quanto aquilo que diz respeito ao percurso sobre as posições, existem: mudanças de zonas; passagem de uma fronteira a outra; passagens de fronteira à zona ou o inverso; manutenções dentro de posição (para uma operação de conservação). Damos exemplos dos principais percursos:

1. De zona em zona: por exemplo, da identitária, passando pela proximal, a caminho da distal "eu sou um outro" (célebre frase do poeta Rimbaud);

2. De fronteira a fronteira: por exemplo, o fetiche se tornará ídolo, o que acontece na divinização do dinheiro, na hipérbole da publicidade;

3. De fronteira a zona: por exemplo, o ídolo integrará a zona dos congêneres em Deus, Shakespeare e eu, titulo de Woody Allen (em uma primeira interpretação possível onde Deus torna-se um congênere humano); outro exemplo, Jesus se fará homem e tornar-se-á congênere;

4. De zona a fronteira: por exemplo, o elemento identitário se tornará ídolo no mesmo titulo de Allen (em uma segunda interpretação possível onde o "eu," de maneira irônica, torna-se igual a Deus).

\footnotetext{
${ }^{6}$ Os mesmos princípios gerais - inventários das posições, classificações nas posições, percursos, fatores de relatividade - valem para outros dispositivos de análises se não para todos: modelo actancial, esquema narrativo canônico, quadrado semiótico, esquema tensivo, etc.
} 
Diferentes efeitos, normalmente sérios ou engraçados (como vemos em nossos exemplos), são produzidos por esses cursos.

\section{Resumo e análise do texto}

Não daremos a referência (titulo, autor, etc) da sādhana estudada. Efetivamente, o mestre tibetano, graças a quem, tomamos conhecimento do texto, disse-nos que não queria "publicidade". Nós analisamos o texto em sua tradução francesa. Embora essa sādhana pareça trazer mais elementos do que a sādhana média do mesmo tipo, na verdade, ela não contém elementos que se pudessem encontrar, comumente, em outras sādhanas do mesmo tipo.

As sādhanas sempre comportam três partes: Os preliminares (ou a preparação), a parte principal e a conclusão (Cornu, 2006: 491 - 492). O texto em análise não é exceção.

\section{Preparação}

1.1 Recomendação. O texto recomenda: "instale-se em uma almofada confortável no lugar de sua escolha. Examine sua motivação e gere uma atitude particularmente positiva." (p.7)

1.2 Motivação. A motivação correta de toda a prática espiritual no âmbito do Mahāyāna, sobre o qual se funda o tantrismo de Buda, é atingir a iluminação para o benefício de todos os seres sensíveis. Os seres sensíveis, em última análise, são aqueles que têm disposição para o sofrimento, incluindo, seguramente, os humanos, como também, os animais, os deuses, os semideuses, os espíritos famélicos, os condenados. Vê-se que o budismo Mahāyāna amplia, consideravelmente, a zona dos congêneres, a zona proximal. Além disso, como veremos mais adiante, esta zona, vem a integrar a zona identitária e/ou ser mais valorizada que ela. O praticante se visualiza aqui com uma infinidade de seres, seus congêneres da zona proximal. Pode-se o presumir que ele pode, deve caminhar assim durante toda a prática em curso. Esta inclusão de todos os seres sencientes, simultaneamente, como finalidade da prática e como co-praticantes, permite reduzir a intensidade da prática e diminuir o possível egocentrismo.

1.3 Recitação. Efetuam-se três recitações da oração do espírito do despertar ou da bodhicitta, ou seja, o desejo de alcançar a iluminação para o benefício de todos os seres sencientes. Aqui, o praticante faz o voto de agir "por todos os meios para que todos os seres" (p.7) atinjam a iluminação, ou de obter os meios para atingir a própria 
iluminação . De fato, uma vez que a iluminação foi alcançada, o poder de ajudar seres sencientes é reduzido.

1.4 Visualização. O praticante visualiza diante dele seu mestre sobre o aspecto de Avalokiteśhvara (o bodhisatva da compaixão). O mestre Avalokiteśhvara é cercado pelos mestres da linha [sucessão ininterrupta de mestres para discípulos], desde a origem até os dias atuais,/ Os yidam [tutores budistas dos praticantes], os budas, os bodhisattvas, [dhyamis bodhisattvas, presume-se que sejam emanações de budas], dakas e dakinis [equivalentes tântricos dos bodhisattvas que podem estar iluminados ou não e os protetores que possuem o olho da sabedoria [ou seja, que atingiram a iluminação em oposição aos protetores mundanos]. (p.9).

Nota-se que o mestre é, ou totalmente ou principalmente (se os dakas e os dakinis presentes não estejam totalmente iluminados), rodeado de seres iluminados como o é, ele próprio, tanto quanto o Avalokiteśhvara (isto não quer dizer que o mestre particular invocado tenha atingido a iluminação). O mestre passou, portanto, da zona dos "congêneres" à zona distal, aquela da transcendência. Os seres da zona proximal pessoal, pelo menos de sua porção mais imediata, são, como ele, seres transcendentes em relação ao praticante. Vê-se bem aqui a relatividade dos pontos de vista. O mestre está, ao mesmo tempo, na transcendência e é mediador daquela, um ídolo para o praticante: ele está, portanto, sobre a fronteira transcendente e além dela.

Existem duas maneiras de conceber a fusão do mestre com Avalokiteśhvara: os dois estão fundidos ou, ainda, como parece indicar o texto, o ser do mestre é o mesmo, mas seu parecer está transformado, revelando seu verdadeiro ser, aquele de um iluminado totalmente compassivo. Neste caso, não existe fusão de dois seres, mas fusão de um novo parecer com o mesmo ser.

1.5 Convite: "todos os seres das seis classes de existência [os humanos, os animais, etc] e eu mesmo, nós lhe [ao mestre Avalokiteśhvara e ao seu entorno divino] endereçamos, respeitosamente, esta prece: [....]/ Por amor a nós, mostrai as inumeráveis formas / E vinde neste lugar onde, com devoção, nós vos fazemos oferenda" (P.9)

Se o mestre for intensificado, tornando-se Avalokiteśhvara, o praticante será igualmente intensificado (mas, permanecendo ele próprio), unindo-se á multidão da qual ele torna-se o porta - voz. A multidão dos budas corresponde, então, a multidão dos necessitados de assistência. A multidão está ela própria, igualmente, no Avalokiteśhvara porque, na forma utilizada na sādhanna, ela dispõe de quatro braços, evidentemente, para sublinhar seu desejo de ajudar os seres e sua aptidão para fazê-lo e traz, sobre sua 
cabeça, o buda, do qual ele emana, Amitābha. Encontram-se, assim, dois personagens duplos: o mestre Avalokiteśhvara corresponde a Avalokiteśhvara - Amitābha. Em relação ao praticante, existem, assim, três "distancias": o ser mais próximo é, evidentemente, o mestre seguido do Avalokiteśhvara e, enfim, Amitābha. O mestre exerce, então, o papel de ídolo, de intermediário entre o praticante e Avalokiteśhvara e, este último, o papel de ídolo entre o praticante e Amitābha. Amitābha constitui, aliás, ele próprio, um mensageiro, uma manifestação, uma ajuda e uma representação da transcendência que o praticante procura atingir e, portanto, um ídolo.

1.6 Oração ao mestre: O praticante abre "corpos tão numerosos quanto os átomos do universo" (p. 9) para invocar o mestre, proclamar e louvar suas qualidades. Vê-se aqui que a redução é interna: não são mais outros seres sensíveis que se unem ao praticante, (mas) é o próprio praticante que se reduz para aumentar o valor e os efeitos de sua louvação. O praticante encontra-se, portanto, a povoar e a saciar a zona proximal a partir do próprio centro da zona identitária: ele próprio. Veem-se, pois, dois tipos de reduplicação. Na primeira, uma forma se reduplica em uma forma diferente: o mestre em Avalokiteśhvara e Avalokiteśhvara em seu entorno (com efeito, uma vez que, como veremos mais adiante, o entorno se fundamentará em Avalokiteśhvara, pode-se presumir que o entorno não é, definitivamente, se não uma emanação deste aqui). No segundo tipo, uma forma se reduplica em uma forma idêntica.

Uma das qualidades do mestre é estar "vindo para amar os outros mais que [a si] próprio" (p.11). O jogo espiritual funciona aqui sobre as duas primeiras zonas cuja valorização, para o sujeito, se modifica e acaba mesmo por se inverter. SwâmiPrajnânpad, um mestre advaïta vedanta (uma tradução que não é budista), esquematizou, de maneira impressionante, aquilo que é o percurso em direção á verdadeira compaixão: “eu, unicamente, eu e os outros, os outros e eu, os outros unicamente" (apud Desjardins, 2003:121). A zona dos congêneres, a proximal, torna-se mais importante que a zona identitária e isto, graças a integração com a zona distal. A prática Mahāyānadu tonglen (tib.: a mudança de si mesmo e dos outros) vai nesta direção:

A primeira [etapa] consiste em reconhecer no outro a mesma importância de si mesmo: os outros todos como voz, aspiram à felicidade e não querem sofrer. Deveis, portanto, desejar sua felicidade, da mesma forma que desejais a vos próprios e desejar que eles escapem do sofrimento. A segunda etapa é a mudança de si mesmo e dos outros: desejai que os outros possam atingir vossa felicidade e que vos podeis tomar seu sofrimento. A terceira etapa 
consiste em querer bem aos outros mais do que a si mesmo, á semelhança dos grandes bodhisattva (DilgoKhyentsé Rinpotché, 2008:129)

Depois, o praticante faz a oferenda do mandala (um ritual de oferenda) e recita “o apelo das bênçãos", ou seja, a oração para a linhagem "[dos mestres da prática em questão]" (p. 15). Ele invoca, antes, ŚāKyamuni (isto é, o Buda, o fundador do Budismo), o budista, símbolo da sabedoria Mañjuśhrī, grandes mestres indianos (Nagarjuna, Asanga) e todos os bodhisattvas, "da longa tradição indiana e tibetana" e, para terminar, o mestre do praticante. No final de cada grupo de representantes da linhagem, recita-se "nós vos rezamos para que possamos realizar o bem dos seres" (p. 15-17), tornando-se "vosso igual, bodhisattvas" (p.19). Fica, portanto, claro que o ponto culminante da linhagem é, portanto, o praticante: a linhagem resulta da zona identitária.

Pedem-se as bênçãos da linhagem para que "renunciemos ao mundo por medo do sofrimento / E nos desapeguemos, com repugnância, dos prazeres do samsāra e do nirvāna" (p.17). Aqui o nirvāna repugnante que é questionado é o nirvāna chamado estático. Com efeito, no Mahāyāna, distinguem-se o nirvāna estático (a libertação) do nirvāna dinâmico (a iluminação). Segundo está escola, é necessário ultrapassar o primeiro para atingir o segundo, onde se fica, ao mesmo tempo, no nirvãna pela sabedoria e no samsāra (nosso mundo condicionado) pela compaixão por aqueles que sofrem.

Excetuando o Mañjuśhrī, todos os seres enumerados tiveram uma existência histórica e são humanos que têm, como principio, atingir a iluminação (para atrair os benefícios plenos, é necessário, no minimo, vê-los como tais). Estes mestres, pelo menos para os mestres que têm uma existência histórica, são, evidentemente, congêneres, mas eles se distinguem uns dos outros por maior ou menor distanciamento temporal, ou seja, a maior ou menor integração na zona de ausência, a zona distal. Como se vê, a participação numa zona pode ser gradual (graus diferentes de pertecimento a uma zona podem ser distintos) e inverso (quanto mais se pertence a uma zona, menos se pertence à outra, etc). Estes mestres são, igualmente, idolos que permitem ascender à transcedencia. Em resumo, eles também se abrigam na transcendência e nela são os mediadores.

Neste momento da prática, fenômeno, sem dúvida, tornado possível por conta do fervor e da pureza da oração, visualiza-se que

"A sílaba Hrīh presente no coração do mestre Avalokiteśhvara mestres, etc enumerados acima]". Este último se fundamenta em luz e se dissolve no 
mestre Avalokiteśhvara que aparece, então, no alto da minha cabeça, brilhante, feliz e sorridente. (p. 19)

Dito de outra forma, a zona proximal do mestre Avalokiteśhvara foi integrada na zona identitária pelo viés de uma luz fetiche e o mestre Avalokiteśhvara se aproxima, "fisicamente", do praticante, numa contiguidade física que se assemelha àquela dos congêneres mais próximos (parentes, cônjuges, amigos), partes interessadas, no limite da zona identitária. Para melhor marcar, entretanto, a diferença que separa as duas entidades, a parte mais nobre do praticante no budismo, sua cabeça, está em continuidade com os pés da divindade, a parte mais "impura" daquele.

O praticante imagina-se, de novo, "com todos os seres, [seus] parentes (P.19)". E eles oram ao mestre com uma "única voz" (p. 19), seguido de uma oração ao Avalokiteśhvara que enumera as qualidades espirituais em dísticos, cada um dos quais é concluido pelo verso "Precioso Mestre, nós oramos a vós".

Como o praticante conheceu um grande número de encarnações desde tempos infinitos, todos os seres sensíveis, em um momento ou em outro, foram seus pais e mães benevolentes. Ele, portanto, somente deseja pagar-lhes em retribuição a sua bondade. Os congêneres, inclusive seres desconhecidos e inimigos, quando considerados pais do praticante, são trazidos da zona próxima para integrar a zona identitária. É assim que o mestre - Avalokiteśhvara, sempre na visão do praticante, produz uma grande quantidade de néctar de cinco cores que escorre do corpo da divindade e preenche o corpo e o espírito do praticante, purificando-o de "todos os atos negativos e obscuros acumulados desde tempos imemoriais" (p. 21).

Dito de outra forma, embora um pouco mais que antes, a luz que havia permitido colocar em fusão as divindades no mestre- Avalokiteśhvara, ou seja, a integração de sua zona proximal à identitária é agora o néctar luminoso que funciona no papel de mediador para o praticante. A luz serve, portanto, para fundamentar e concentrar a energia espiritual e purificá-la. O praticante, integrando o mediador dentro do seu corpo, aproxima-se da zona distal, estando, por conseguinte, preparado para a prática principal.

\section{Prática principal}

2.1. Em consequência de sua preparação, o praticante recebe as iniciações habituais (aqui autoiniciações), sejam aquelas do corpo, da palavra, do espírito e a quarta iniciação. Ele se imagina fundir-se com a divindade, naquele que se encontra em alguma das "três portas", seja o corpo, a palavra e o espirito: "Vosso corpo e o meu 
tornam-se inseparáveis/Vossa palavra impregna minha palavra/Vosso espirito se mistura ao meu" (p. 157).

O mestre- Avalokiteśhvara fundiu-se nele: "Eis-me aqui Avalokiteśhvara" (p.157). O praticante integrou, na zona identitária, outro que se tornou ele e atinge por ele a zona distal que este outro percorreu para o benefício do praticante. Do praticante, emanam, então, "raios de luz que atingem todos os seres" e estes manifestam, então, "todos sob a forma de Avalokiteśhvara" (p. 157).

Observa-se, ainda, que são os raios luminosos que emergem de uma entidade central em direção às entidades periféricas para, mais uma vez, as transformarem: em um caso pela fusão e em outro pela transformação com o idêntico. Mais uma vez, a prática é multiplicada, igualmente desindividualizada e estendida a todos os congêneres no sentido mais amplo, ou seja, a todos os seres sensíveis. As zonas identitárias de cada ser e as zonas proximais associadas estão, por assim dizer, vazias em proveito da zona distal: unicamente existe a transcendência. Com efeito, pode-se considerar um movimento de imanentização da transcendência ou, ainda, de transcendentização da imanência. Qualquer que seja ela, aqui se atinge este momento mítico e apoteótico - e, sem dúvida, utópico e simbólico, uma vez que o samsāra não tem, parece, nem começo nem fim — onde todos os seres, tendo atingido o encantamento, terão deixado o samsāra. Entre tempos, como o diz Shāntideva (apud RICARDO, 2005:137), o praticante desejará: "um tempo tão longo enquanto existir o espaço/ Também tão longo enquanto houver os seres/Que possa, eu também, permanecer [no samsāra]/Para dissipar a dor do mundo".

Enfim, o praticante terá, sucessivamente, visualizado o mestre - Avalokiteśhvara diante dele, em cima de sua cabeça, penetrando-o pelo néctar luminoso e, finalmente, fundindo-se com ele. A primeira etapa é, evidentemente, aquela, na qual a divindade não apareceu, ainda, diante dele.

No catolicismo, a divindade é integrada pelo alimento, pão e vinho. Aqui, a integração se faz, igualmente, por um elemento do tipo alimentar, um néctar. Entretanto, no primeiro caso, salvo engano segundo a tradição teológica, aquele que recebe o alimento não se torna Cristo, enquanto que, no segundo caso, o que o recebe torna-se Avalokiteśhvara.

2.2 O praticante recita, em seguida, o mantra de Avalokiteshvara tantas vezes quanto possível: "Om manipadméhoung" (pronunciado pelos Tibetano "om manipeméhoung"). 
Por fim, ele deve "permanecer sem conceitos" (p.157) o que quer dizer fora do pensamento dual, condicionado.

\section{Conclusão da prática}

3.1 Para terminar, o praticante procede a dedicatória dos méritos, o que quer dizer dá aos seres o Karma positivo acumulado através prática. Ele deseja que o mérito lhe permita atingir a iluminação e que todos os seres, sem exceção façam o mesmo, Dito de outra forma, ele reza para que sua visualização se torne realidade. Ele deseja, também, que o mérito acumulado lhe permita obter, em suas vidas sucessivas, "um precioso corpo humano" (p.159) e que ele seja, então, ajudado por um mestre espiritual. Toda a existência no Samsāra é sofrimento e, com este título, não é desejável. O suicídio é excluído porque não coloca um termo nos sofrimentos, (reencarna-se) e, o que é pior, amplificam-se (acumula-se o mau Karma com estes gestos) de todos os tipos de existência possíveis (animais, deuses, condenados, etc), diz-se que é a vida humana que fornece a melhor oportunidade para atingir a libertação e o encantamento e, portanto, de se extrair do samsāra (e estar, assim, ao alcance de melhor ajudar os outros sem afastar-se ). O praticante reza, portanto, para renascer humano e, já que a liberação e a iluminação para si são quase impossíveis (ou mesmo impossíveis, no dizer de outros) para reencontrar-se num contexto onde possa ser guiado por um mestre autêntico.

O praticante invoca, em seguida, os mestres, os yidams, os dakas e os dakinis, os protetores e guardiões do dharma, para que se reúnam "em nuvens de compaixão" (p.159) e prodigam "uma chuva densa de bênçãos" (p.159). Nota-se que este encerramento invoca, grosso modo, as mesmas entidades do início cujo caminho foi, entretanto, percorrido depois. O praticante tornou-se, através de sua visualização, transcendente igual àqueles que ele invocava no inicio do fim, fundo obscuro de sua iminência.

3.2 Enfim, pede-se, ao praticante, para concluir "com desejos positivos de um bem-estar temporal e último" (p.159), sendo o bem estar - último, evidentimente, obtido por iluminação. O mestre que nos fez conhecer esta sādhana surgere, para fazêla, recitar um texto particular, costituido de breve oração de conclusão sobre o crescimento do "espirito do iluminado" e uma oração pela longa vida de todos os mestres. 


\section{Conclusão}

O mestre, pelo menos em sua nirmanakāya, como veremos mais adiante, é um congênere. Tomando, na visualização, a forma da divindade praticada, Avalokiteśhvara torna-se um ídolo que representa a transcendência e permite atingi-la. O mestredivindade se aproxima, progressiva e fisicamente, do praticante (sucessivamente: "ausente, em face dele, abaixo dele, em contato, pelo néctar, com ele, nele, até ele próprio"). Este "abaixamento" tem por corolário a "elevação" do praticante que se torna, no fim, idolo idêntico. Nesta transformação, engloba: todos os seres sensíveis que apelam para a transcendência, todos os seres sensíveis que a recebem, todos os seres sensíveis que se tornam a transcendência, tornando-se o mestre divindade. O mestredivindade se simplificou para "invadir" a totalidade das zonas identitaria e proximal do praticante; ele tinha, anteriormente, reabsorvido sua própria zona proximal, integrandoa, condensando seu próprio entorno sublime. O praticante, igualmente, povoou, de inumeráveis eles próprios, sua zona identitária que transborda de alguma forma sobre a zona proximal: depois de tudo, estes são eles próprios com mais outros eles próprios. Finalmente, entre outros procedimentos, fala-se que a visualização opera uma redução da diversidade dos seres da zona próximal e da fronteira transcendente e um aumento dos seres da zona identitária, em principio, povoada por um único ser.

Uma sādhana implica três tipos de performances. Primeiramente, a sādhana é um texto que chama para uma leitura. Neste sentido, as unidades que revelam as três zonas e as duas fronteiras consistem em unidades tematizadas, integradas nos conteúdos semânticos ou semióticos (por oposição aos conteúdos (re)presentacionais).

Mas este texto é, antes de tudo, uma partitura, ou seja, ele serve de suporte a uma performance ritual "externa", além da simples leitura feita em voz alta. Esta segunda performace engaja o pensamento (as visualizações, as atitutes mentais, etc), a palavra (as mantras e outros textos verbais) e a ação (a oferenda do mandala que comporta gestos ordinários e mudrãs, ou seja, gestos simbólicos). Neste sentido, a sadãna implica os três níveis de uma prática: o feno-físico, o semiótico e o (re)presentacional.

Esta complexa coreografia é repetida, constantemente, para que, com sua ajuda e com ajuda daqueles existentes em outras práticas e ações meritórias, a transformação chamada, visualizada e sentida se transforme em realidade, o que constitui a terceira performance. Quando a transformação se opera e o praticante atinge, portanto, a 
iluminação, ele produz três corpos ou kāyas. Por seu dharmakāya (ou corpos absoluto), ele entra numa insondável e indizivel transcendência, logo está além do idolo, ele se encontra na zona distal e não na sua fronteira. Mas, pela sua compaixão, "o novo" Buda "produz" dois rupakkāyas (ou corpos formais), dois idolos, que vão trabalhar para o bem dos seres "restantes" no samsāra: o sambogakāya (ou corpo de gozo), perceptível, unicamente, pelos grandes boddhisattvas da oitava à décima terra ${ }^{7}$, e o nirmanakāya (ou corpos de aparição), a manifestação ordinária de um mestre (iluminado) pelos seres ordinários (o mestre iluminado nos aparece como um ser humano igual a nós).

\section{Referências}

BINET, A. (2001) [1887], Le fétichisme dans l'amour, Paris, Payot.

COMITÉ DE TRADUCTION PADMAKARA (le) (2008), «Glossaire» dans DilgoKhyentsé Rinpotché, Au cour de la compassion. Commentaire des Trente-sept stances sur la pratique des bodhisattvas, Le Plantou (France), Padmakara.

CORNU, P. (2006), Dictionnaire encyclopédique du bouddhisme, Paris, Seuil.

DESJARDINS, A. (2003), Les formules de SwâmiPrajnânpad commentées par Arnaud Desjardins, Paris, La Table Ronde.

DILGO KHYENTSE RINPOCHE (2007), The Heart of Compassion. The Thirtyseven Verses on the practice of a Bodhisattva, Boston et Londres, Shambala.

DILGO KHYENTSÉ RINPOTCHÉ (2008), Au cœur de la compassion. Commentaire des Trente-sept stances sur la pratique des Bodhisattvas, Le Plantou (France), Padmakara.

HÉBERT, L. (2011a), «Sémiotique et bouddhisme. Carré sémiotique et tétralemme (catuskoti) », dans L. Hébert et L. Guillemette (dir.), Performances et objets culturels, Québec, Presses de l'Université Laval, p. 103-128.

HÉBERT, L. (2011b) (dir.), Sémiotique et bouddhisme, Protée, 39, 2, automne.

HÉBERT, L. (2011c), «Sémiotique et bouddhisme : quelques repères», dans L. Hébert (dir.), Sémiotique et bouddhisme, Protée, 39, 2, p. 5-8.

HÉBERT, L. (2011d), «Opérations de transformation dans l'iconographie du bouddhisme tibétain», dans L. Hébert (dir.), Sémiotique et bouddhisme, Protée, 39, 2, p. 81-94.

HÉBERT, L. (2011e), «Les opérations de transformation» [version augmentée de Hébert 2011d], dans Louis Hébert (dir.), Signo [en ligne], Rimouski (Québec), http://www.signosemio.com/operations-de-transformation.asp.

HÉBERT, L. (à paraître a), «Becoming a Buddha: a Semiotic Analysis of Visualisations in Tibetan Buddhism», dans A. S. Kohav (dir.), Mysticism and

\footnotetext{
${ }^{7}$ As dez terras são níveis de desenvolvimento espiritual que antecedem a iluminação. Na primeira terra, atinge-se à liberação (isto quer dizer que se escapa das encarnações involuntárias); depois, na segunda terra, atinge-se a iluminação. Da primeira terra à seguinte, os poderes e evolução espiritual se amplificam.
} 
Meaning: Philosophy, Semiotics, Historical, and Linguistic-Literary Approaches, New York, Oxford University Press.

HÉBERT, L. (à paraître b), «La compassion en général et dans le bouddhisme en particulier. Définitions et typologies».

HÉBERT, L. (à paraître c) «Sémiotique du nirvāṇa. Le salut dans le bouddhisme», dans T. Broden et S. Walsh Matthews, Greimas [titre de travail], Semiotica.

POMIAN, K. (1996), «Histoire culturelle, histoire des sémiophores», dans J.-P. Rioux et J.-F. Sirinelli (dir.), Pour une histoire culturelle, Paris, Seuil, p. 73-100.

RASTIER, F. (1991), Sémantique et recherches cognitives, Paris, Presses universitaires de France.

RASTIER, F. (1992), «Réalisme sémantique et réalisme esthétique», Théorie, littérature, enseignement, 10, p. 81-119.

RASTIER, F. (2002), «Anthropologie linguistique et sémiotique des cultures», dans F. Rastier et S. Bouquet (dir.), Une introduction aux sciences de la culture, Paris, Presses universitaires de France, p. 243-267.

RASTIER, F. (2010), «Objets culturels et performances sémiotiques. L'objectivation critique dans les sciences de la culture», dans L. Hébert et L. Guillemette, Performances et objets culturels, Québec, Presses de l'Université Laval, p. $15-58$.

RASTIER, F., M. CAVAZZA et A. ABEILlÉ (1994), Sémantique pour l'analyse, Paris, Masson.

RASTIER, F. Ação e sentido por uma semiótica das culturas. Tradução do original Laction et le sens pour une sémiotique des cultures: Maria de Fátima Barbosa de Mesquita Batista. João Pessoa, Ideia/Editora Universitária da UFPB, 2010.

RICARD, M. (2005), La citadelle des neiges, Paris, Nil.

UEXKÜLL, J. V. (1956) [1934], Mondes animaux et mondes humains, Paris, Denoël. 